\title{
GAIA Level 1 Postnatally Diagnosed Congenital Microcephaly
}

National Cancer Institute

\section{Source}

National Cancer Institute. GAIA Level 1 Postnatally Diagnosed Congenital Microcephaly. NCI Thesaurus. Code C128757.

GAIA Level 1 Postnatally Diagnosed Cong enital Microcephaly is defined by three criteria: first, a live birth, stillbirth, or spontaneous or therapeutic abortion of at least 24 weeks Gestational Age (GA), with GA assessed by either a certain last menstrual period (LMP) date with confirmatory 1st trimester (less than 14 weeks) or 2 nd trimester ultrasound (US) scan OR intrauterine insemination (IUI) OR embryo transfer date; second, a head circumference $(\mathrm{HC})$ measurement either 2 standard deviations (SD) below the mean or less than the third percentile as assessed by GA and gender, using appropriate, standardized reference charts for the population (e.g. WHO growth reference charts if GA greater than or equal to 37 weeks and Intergrowth-21st reference charts for GA 24 to 36 weeks); third, the measurement is taken either between 24 and 36 hours after birth or at the end of the pregnancy. 